\title{
Desafios para a inserção da tecnologia na Educação Física escolar
}

\section{Challenges for the insertion of technology in school Physical Education}

\author{
Kátia Martins Soares ${ }^{1 *}$, Liane Margarida Rockenbach Tarouco ${ }^{1}$, Patrícia Fernanda Silva ${ }^{1}$
}

\section{RESUMO}

A inserção das tecnologias digitais no componente curricular de Educação Física é uma referência da Base Nacional Comum Curricular desde 2018, entretanto por motivos diversos, tem-se demonstrado tardia. Nesse aspecto, este trabalho tem o objetivo de verificar quais tecnologias estão sendo empregadas e suas contribuições no desenvolvimento do ensino e aprendizagem. A partir da análise de pesquisas no período de 2015 a 2021 presentes na base de dados da revista Scopus e Google Scholar, utilizando os descritores: "physical education and technology", "physical education and information and communication technology" foram encontrados 10 artigos. Os resultados apontam o crescimento de trabalhos envolvendo o uso da Tecnologia, com investigações sobre o estado da arte citando Jogos Digitais, Realidade Virtual e Aumentada, uso de Exergames, tecnologias de ampla usabilidade, como Boomerang do Instagram, Câmera $360^{\circ}$, leitor de QR code, Tecnologia Vestível (Wearable Technology), além de estudos para contribuições na saúde e envolvimento em atividades físicas que incorporam as tecnologias digitais.

Palavras-chave: Tecnologias digitais; Educação Física; Aprendizagem; Inserção digital.

\begin{abstract}
The insertion of digital technologies in the curricular component of Physical Education has been a reference in the Common National Curriculum Base since 2018, although for different reasons, it has been lately rescheduled. The insertion of digital technologies in the curricular component of Physical Education has been a reference in the Common National Curriculum Base since 2018, although for different reasons, it has been lately rescheduled. In this aspect, this work aims to verify which technologies are being used and their contributions in the development of teaching and learning. From the analysis of research from 2015 to 2021 present in the database of the Scopus and Google Scholar magazine, using the descriptors: "physical education and technology", "physical education and information and communication technology" 10 articles were found. The results show the growth of works involving the use of Technology, with investigations on the state of the art citing Digital Games, Virtual and Augmented Reality, use of Exergames, technologies with wide usability, such as Boomerang from Instagram, $360^{\circ}$ Camera, QR code reader, Wearable Technology, in addition to studies for contributions to health and involvement in physical activities that incorporate digital technologies.
\end{abstract}

Keywords: Digital technologies; Physical Education; Learning; Digital insertion.

\footnotetext{
${ }^{1}$ Universidade Federal do Rio Grande do Sul.

*E-mail: prof.katiasoares@gmail.com
} 


\section{INTRODUÇÃO}

A utilização das tecnologias digitais na mediação no desenvolvimento do ensino e aprendizagem tem sido lenta e gradativa. A capacidade das Tecnologias da Informação e Comunicação (TIC) de potencializar a comunicação e gerar novas formas de proposição de conteúdos didáticos nem sempre são acompanhadas pelos professores. Contudo, uma reflexão sobre o potencial da tecnologia torna-se necessária, com vistas a uma educação atualizada e conectada com os avanços contemporâneos.

De acordo com pesquisas recentes, as dificuldades para a inserção da tecnologia na escola passam por motivos administrativos; estruturais (faltam computadores e internet); e formativos, bem como a necessidade de formação inicial e continuada, que promovam o uso da TIC; financeiros (SOARES, 2019). Demais estudos apontam que a Educação Física é uma das disciplinas que vem encontrando barreiras para a apropriação da tecnologia no espaço escolar. Seja por falta de formações, como mencionado acima, ou pela própria especificação desta área de estudo, que tem seu cerne no movimento corporal (FUZARO, SANTOS e MONTEIRO, 2021; FUKUGAUTI e PAVAN 2020).

A fim de dirimir possíveis dúvidas quanto à conceituação de tecnologia, tecnologia da informação e tecnologias digitais, utilizou-se o respaldo da BNCC (2018) considerando-as como correlatas em relação aos recursos tecnológicos. A BNCC aglutinou os termos tecnologia digital e tecnologias da informação e comunicação para: as Tecnologias Digitais da Informação e Comunicação (TDICs). Complementando o conceito com o dicionário Oxford a tecnologia: num sentido global é o estudo sistemático sobre as técnicas e os processos que permeiam a atividade humana. Em vista disso, estas acepções serão consideradas como sinônimas em relação ao uso no ambiente escolar.

A Base Nacional Comum Curricular BNCC (2018) contempla em suas diretrizes o desenvolvimento de competências e habilidades relacionadas ao uso correto e equilibrado das tecnologias digitais, subdividindo-a na forma transversal (todo contexto do conhecimento e desdobrando-se em objetos de aprendizagem variados); ede maneira orientada, ou seja, com uso e criação de TDICs em diversas práticas sociais.

A Base Nacional Comum Curricular (2018) é um documento de referência em vigência para a educação brasileira, apresenta os jogos digitais (também nominados na BNCC como jogos eletrônicos e games) como conteúdo a ser trabalhado em diferentes etapas de ensino e componentes curriculares (Língua Portuguesa, Artes e Educação Física). Neste sentido, é uma prerrogativa a inserção das tecnologias digitais, considerando que os jogos digitais aparecem na Educação Física prevista nos $6^{\circ}$ e $7^{\circ}$ anos do Ensino Fundamental (BRASIL, 2018). 
Neste aspecto, o presente estudo tem o objetivo de investigar quais tecnologias estão sendo empregadas na Educação Física e quais relações com a aprendizagem. Para cumprir este objetivo foi realizada uma Revisão Sistemática (RS) é uma apropriação do Referencial Teórico que subjaz este campo de atuação, considerando-se a referência dos Parâmetros Nacionais Curriculares (1998) e da Base Nacional Comum Curricular (2018).

Na seção 2 são contextualizados os documentos referidos. Na seção 3 apresenta-se a metodologia do estudo. A seção 4 demonstra um resumo de cada artigo e uma tabela com os trabalhos pesquisados. Na seção 5 é realizada uma análise a partir das reflexões disparadas após a leitura dos trabalhos correlatos e o referencial apresentado, finalizando com as considerações finais.

\section{REFERENCIAL TEÓRICO}

Esta seção comporta os documentos e leis que conduzem a educação no Brasil, como os Parâmetros Curriculares Nacionais, que são normas elaboradas pelo Governo Federal, separados por disciplina, neste caso da disciplina de Educação Física. A Base Nacional Comum Curricular (2018) outro documento normativo e mais atualizado para os estabelecimentos de ensino, incluindo as instituições públicas e privadas. A BNCC é uma indicação obrigatória para elaboração dos currículos escolares e projetos pedagógicos para o ensino Básico no Brasil.

\section{OS PARÂMETROS CURRICULARES NACIONAIS}

A caracterização da área da Educação Física escolar no século XX no Brasil sofreu influência da filosofia, do cenário político, do desenvolvimento cientifico e pedagógico. Desta forma, até 1950, a Educação Física, foi influenciada pela filosofia positivista, que almeja na ordem e na Ciência o progressso social, também foi afetado pelas mudanças no próprio pensamento pedagógico, da vertente da escola-novista na década de 50 (PCN-BRASIL, 1998).

As décadas seguintes foram marcadas pela chegada ao Brasil de modelos de práticas corporais embasados no sistema ginástico alemão e sueco e o método francês. Na década de 70 , novamente o aspecto político dominou as tendências na Educação Física, diante do evento da Copa do Mundo e do referencial de nacionalismo vigente na época. Nos anos seguintes foram priorizadas as atividades que desenvolvessem e aprimorassem as capacidades físicas, bem como os aspectos morais, psicológicas e sociais do aluno. Nesta época, a ênfase era a melhoria da saúde, focada na organização, controle e avaliação das atividades, com objetivo à iniciação esportiva. Contudo, o Brasil não se transformou numa referência nos esportes, e a partir de 1980 este modelo começou a sofrer críticas, que se opunham à vertente mais tecnicista, esportista e biologista. 
Analisando-se os Parâmetros Curriculares Nacionais (PCNs-BRASIL, 1998), têm-se as tendências que dominaram a Educação Física após 1980: abordagem psicomotora, abordagem construtivista, abordagem desenvolvimentista, abordagem crítica e o quadro atual (BRASIL, 1998). Apresentando-se as ideias nas quais as abordagens delinearam-se: a psicomotricidade pretendia a relação da Educação Física e do movimento corporal com os aspectos cognitivos , afetivos e sociais da criança.

Na concepção construtivista, o conhecimento é relacionado à interação do homem com o mundo que o cerca; e no desenvolvimento infantil a criança precisa agir sobre o mundo, para então elaborar o seu conhecimento. Na Educação Física o enfoque desenvolvimentista relaciona o desenvolvimento motor do aluno, tendo como objetivo propor atividades que estimulem as habilidades motoras de acordo com a faixa etária.

$\mathrm{Na}$ abordagem crítica a Educação Física concentra seu enfoque sobre as transformações sociais, cuja preocupação é as desigualdades sociais. Nesta linha de pensamento são tensionadas antigas práticas da Educação Física, que simplesmente almejava o rendimento físico na escola e fora desta, o culto ao corpo e a boa forma, sem refletir sobre a saúde; por exemplo, e nem sobre o ser humano em suas relações emocionais, psicológicas e sociais.

$\mathrm{Na}$ atualidade, as quatro tendências elencadas vêm se desdobrando em novas propostas pedagógicas, disparada pela reflexão a respeito da realidade das escolas brasileiras e dos professores; os quais, mesmo em situações adversas, continuam se reinventando. Contudo, de acordo com PCN (1998, p. 26): “em muitos contextos, encontra-se a prática de propostas de ensino pautadas em concepções ultrapassadas, que não suprem as demandas e as possibilidades da educação contemporânea".

BASE NACIONAL COMUM CURRICULAR E A TECNOLOGIA NA EDUCAÇÃO FÍSICA

Na busca de atualização da Educação Física, outro documento posterior ao PCN é a Base Nacional Comum Curricular (2018). Nesta referência, a tecnologia vem sendo considerada pela sua capacidade de inovação, a qual postula na área das linguagens (Português, Artes e Educação Física) a sua inserção.

A BNCC (2018) reforça e retoma os jogos digitais, que no PCN foram mencionados como videogames, como potenciais influenciadores da cultura corporal do movimento. Com a implantação da BNCC tem-se uma nova diretriz na concepção das tecnologias digitais, as quais são perpassadas pelo uso responsável na educação. A competência geral retoma a compreensão, uso e criação das tecnologias digitais:

Compreender, utilizar e criar tecnologias digitais de informação e comunicação de forma crítica, significativa, reflexiva e ética nas 
diversas práticas sociais (incluindo as escolares) para se comunicar, acessar e disseminar informações, produzir conhecimentos, resolver problemas e exercer protagonismo e autoria na vida pessoal e coletiva (BNCC, 2018, p.1).

Alinhado à BNCC (2018) tem-se o Currículo de Referência em Tecnologia e Computação, elaborado pelo Centro de Inovação para a Educação Brasileira (CIEB) ${ }^{2}$ cujo objetivo é normatizar e orientar as instituições de ensino e escolas para a inserção da temática: à tecnologia e ensino computacional nas diretrizes curriculares. A proposição da tecnologia nos eixos do currículo perpassa todas as etapas do Ensino Infantil, Fundamental e Médio, e são divididos em: cultura digital (subdivide-se nos conceitos de letramento digital; cidadania digital; e tecnologia e sociedade); tecnologia digital (subdivide-se nos conceitos de representação de dados, hardware e software; comunicação e redes); em relação ao pensamento computacional a subdivisão perpassa os conceitos de abstração; algoritmo; decomposição; e reconhecimento de padrões. A Figura 1 abaixo representa esta divisão:

\section{Figura 1- Representação da Tecnologia na Educação Básica Infantil e Fundamental}

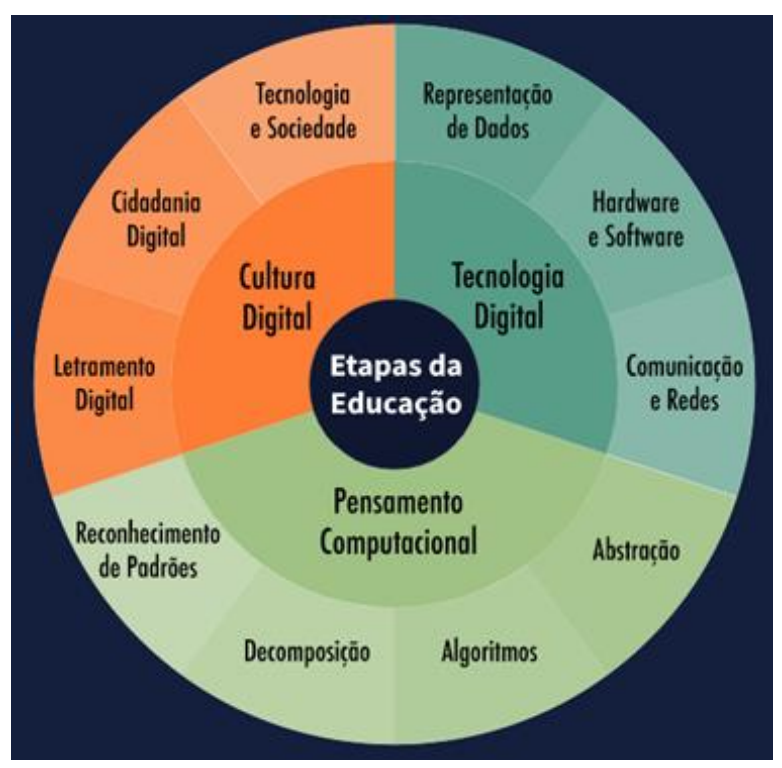

Fonte: BNCC (2018)

De acordo com o CIEB (2018) o Letramento Digital pressupõe as diferentes maneiras de ler, escrever e interpretar informações, códigos e sinais não verbais, mediadas pelo uso das tecnologias digitais. Discorre acerca do desenvolvimento de conhecimentos, habilidades e atitudes pertinentes a aplicabilidade dos insumos digitais com sabedoria. Além disso, almeja que

\footnotetext{
${ }^{2}$ https://curriculo.cieb.net.br/
} 
esta proficiência esteja interligada às práticas socioculturais e que seja permeada de sentidos e reflexões sobre a sociedade e o uso da tecnologia.

Corroborando com a abordagem sobre conhecimentos, habilidades e atitudes, um aprofundamento torna-se pertinente ao considerar as reflexões no estudo desenvolvido por Tarouco $(2013,2019)$ cujas argumentações apontam para o cenário da fluência digital na sociedade do conhecimento. Nestas pesquisas, há uma distinção entre letramento digital e fluência digital, considerando que muitos docentes alcançaram o nível de letramento digital; contudo, para construção e uso da tecnologia são necessárias as aquisições da fluência digital. Tal prerrogativa impõe formações para docentes e maiores investimentos na infraestrutura, com aquisição de computadores, internet, softwares entre outros.

Segundo Tarouco (2019) a alfabetização digital depreende apenas habilidades básicas para o uso de computadores e da internet. Evidenciada pelo uso dos recursos das Tecnologias de Informação e Comunicação (TIC) no papel de consumidores, reforçando a sua autoria ou produção de informação somente em mensagens de texto, via correio eletrônico ou mensagens instantâneas.

Após estudos do Comitê Alfabetização em Tecnologias de Informatização e de revisões conceituais, surge o termo fluência digital conduzindo na direção da fluência com a tecnologia da informação nas palavras da autora: "que caracteriza como fluente aquele que usa, compreende e sabe sobre tecnologia da informação". Isso implica em uma progressão em relação ao que se associa ao conceito de "alfabetização digital" (TAROUCO, 2019, p. 34). A Figura 2 destaca as relações básicas entre os conceitos de alfabetização digital e de fluência digital.

Figura 2 - Alfabetização Digital X Fluência Digital

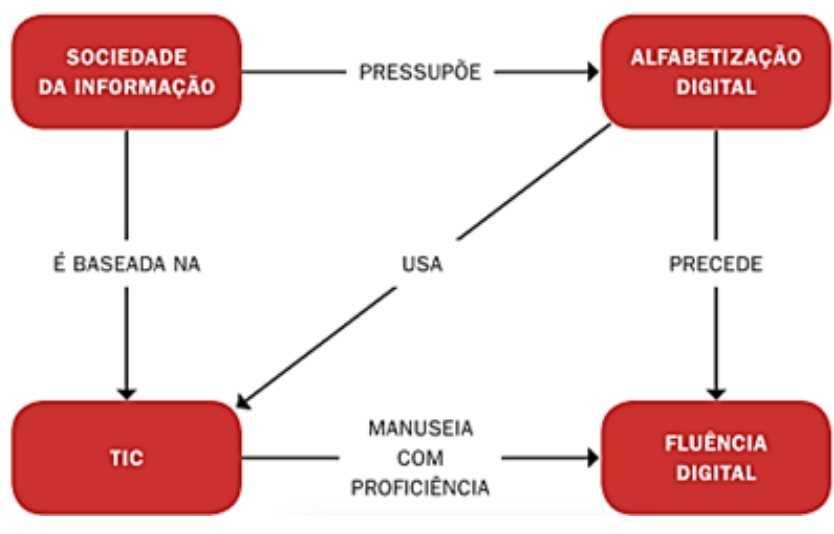

Fonte: Tarouco 2019

Neste sentido, as reflexões levantadas sobre as expressões: alfabetização digital e fluência digital contribuem para compreender o desafio de se inserir a tecnologia no contexto escolar. Não se pretende neste artigo esgotar o assunto sobre o tema, que pode ser consultado em 
profundidade na análise desenvolvida pelo departamento de pesquisa em tecnologia no Brasil TIC-Educação (2019), uma entidade que com o apoio do Ministério da Educação (ME) e do Instituto Nacional de Estudos e Pesquisas Anisío Teixeira (Inep) no artigo: "Competências Digitais dos Professores" (TAROUCO, 2019).

Desta forma, como destacado anteriormente, para que se almeje a fluência digital, requerem-se ações que perpassam por constantes formações iniciais e continuadas, para melhorar e desenvolver a competência digital, bem como uma estrutura com equipamentos atualizada, entre outros requisitos. Além disso, como apregoa a BNCC (2018) as mídias digitais perpassam todas as disciplinas, sendo um direito e um dever a inclusão desta no currículo escolar.

Corroborando para a ampliação do debate dos recursos tecnológicos e com foco nas formações dos docentes, o trabalho atual de Sotili e colaborares (2021) discorreu sobre as aulas on-line e presenciais, modalidade de ensino caraterizado como híbrido, cuja investigação foi realizada em um município de Santa Catarina. Contemplou a formação de professores ao integrar os conhecimentos construídos durante a Especialização em Inovação na Educação, um curso ofertado pela Universidade do Oeste de Santa Catarina (UNOESC). O objetivo do trabalho foi preparar os profissionais da educação para desenvolverem conhecimentos relativos à integração da tecnologia no cenário educativo; desta forma, incorporando-a na pesquisa e na ação docente.

Em seus resultados, a respeito da usabilidade dos insumos instrutivo-pedagógicos, verificaram que os educadores estão dispostos para o aprendizado de novas tecnologias e engajados em usar os novos recursos. Além disso, os educadores mantêm interesse em aprender e utilizar com os estudantes essas novas ferramentas de ensino (SOTILI et al. (2021)).

No que tange à Educação Física, Corrêa (2018) menciona que a utilização das tecnologias auxilia no desenvolvimento de competências e habilidades pessoais, as quais abarcam ações de comunicação, busca de informações, propiciando a autonomia individual, e aumentando as possibilidades de inserções na sociedade da informação e conhecimento.

Os benefícios tecnológicos na Educação Física são demonstrados nos trabalhos correlatos, mas dentre alguns se destacam aplicativos como Exergames, um termo usado para videogames, que ajudam a realizar exercício e possuem um tipo de tecnologia que rastreia o movimento ou a reação do corpo. Além disso, com uso adequado, condicionam capacidades físicas cardiorrespiratórias e musculares e podem ser usados para uso didático na promoção da atividade física (ROHDEN, 2017).

A tecnologia vestível vem ganhando espaço entre usuários, exemplificada pelos Smartband, uma pulseira inteligente ou relógio inteligente que é utilizado durante a execução de 
exercícios físicos para acompanhar as distâncias realizadas. Os sensores incorporados demonstram informações de indicadores de saúde, como frequência cardíaca, gasto calórico e podem contribuir para a motivação às pratica de atividades físicas dos alunos no ambiente escolar e familiar (ALMUSAWI et al. 2021).

Neste aspecto, como destacado anteriormente, unindo-se as formações para docentes às tecnologias acessíveis, que podem ser usadas nos celulares dos próprios alunos, tem-se a potencialidade de incorporar as mídias digitais como elementos inovadores na educação. Este artigo tem como meta verificar quais tecnologias estão sendo empregadas e suas contribuições no processo de ensino e aprendizagem em Educação Física, bem como as barreiras que esta estratégia encontra.

A próxima seção apresenta a metodologia usada nesta investigação que utilizou uma revisão sistemática de literatura. A partir da análise dos resultados, foram elicitadas as principais abordagens encontradas em termos de uso da tecnologia no ensino e aprendizagem de Educação Física. Estes trabalhos foram comentados e uma análise da situação atual no contexto das autoras, foi apresentada.

\section{METODOLOGIA}

O artigo apresenta uma revisão sistemática da literatura sobre o tema. Os critérios de inclusão e exclusão são descritos e elencados neste artigo. As revisões sistemáticas contribuem para avaliar e interpretar uma pesquisa sobre um determinado tema. Neste aspecto, as revisões analisam um conjunto de estudos, aprofundando os conhecimentos já existentes sobre a temática (KITCHENHAM, 2009).

Foram consideradas pesquisas no período de 2015 a 2021, pois como a tecnologia está em constante evolução, admitiu-se a importância de averiguar o uso do que existe atualmente para aprimorar o ensino e a aprendizagem em Educação Física. Foram utilizadas as bases de dados Scopus e Google Scholar com os seguintes descritores: "physical education and technology", "physical education information and communication technology". Os critérios de inclusão são a ocorrência das palavras: tecnologia e educação física, ou tecnologias da informação e comunicação e educação física no título ou resumo dos trabalhos.

A busca no Google Scholar totalizou o resultado 3.050 trabalhos, observou-se que o número expressivo do resultado deve-se à existência de diferentes temas ligados à Educação Física como: esporte de rendimento, prevenção à saúde, danças, jogos, lazer, entre outros. Sendo assim, mantida à especificidade do tema na educação, depois de aplicados os critérios de inclusão e exclusão restaram um total de 41 trabalhos, dos quais foram integrados à pesquisa 8 (oito) trabalhos. Na base de dados da Scopus, de maneira ampla retornaram 4.098 documentos, 
dentre os quais foram selecionados 2 (dois) que tinham no resumo indícios de oferecerem contribuição relevante.

Os trabalhos selecionados estão relacionados Tabela 1- Relação autor, tipo de estudo e tecnologia aplicada, que compõe o título e os autores, bem como os dados detalhados que permitem visualizá-los e compará-los, destacando o tipo de estudo (pesquisa qualitativa ou quantitativa, pesquisa bibliográfica), etapa de ensino que foi aplicada a pesquisa (Ensino Fundamental, Ensino Médio ou Ensino Superior), qual a tecnologia empregada (qual tecnologia usada no estudo) e serão comentados a na próxima seção.

Tabela 1- Relação autor, tipo de estudo e tecnologia aplicada.

\begin{tabular}{|c|c|c|c|}
\hline Estudo, autor e ano & Tipo de estudo & Etapa do ensino & Tecnologia \\
\hline $\begin{array}{l}\text { 1.Tecnologia da Informação } \\
\text { e Comunicação: Novas } \\
\text { Tendências do Ensino na } \\
\text { Educação Física (Fuzaro, } \\
\text { Santos e Monteiro 2021). }\end{array}$ & $\begin{array}{l}\text { Análise bibliométrica do } \\
\text { estado da arte }\end{array}$ & Todos & $\begin{array}{l}\text { Tecnologias da } \\
\text { Informação e } \\
\text { Comunicaçãa }\end{array}$ \\
\hline $\begin{array}{l}\text { 2.Tecnologia na Educação } \\
\text { Física Escolar. Fukugauti e } \\
\text { Pavan (2020) }\end{array}$ & $\begin{array}{l}\text { Pesquisa bibliográfica, } \\
\text { pesquisa documental e } \\
\text { pesquisa de campo com } \\
\text { aplicação de questionário. }\end{array}$ & Ensino médio & $\begin{array}{l}\text { Tecnologia no } \\
\text { Ensino Híbrido }\end{array}$ \\
\hline $\begin{array}{l}\text { 3.The Emergence of } \\
\text { Technology in Physical } \\
\text { Education: A General } \\
\text { Bibliometric Analysis with } \\
\text { a Focus on Virtual and } \\
\text { Augmented Reality. Moreno } \\
\text { et al. (2020) }\end{array}$ & $\begin{array}{l}\text { Levantamento } \\
\text { bibliométrico com análise } \\
\text { de artigos Publicados na } \\
\text { Web Of Science }\end{array}$ & & Realidade virtual \\
\hline $\begin{array}{l}\text { 4.Tecnologias Digitais: } \\
\text { Ferramenta Pedagógica para } \\
\text { as Aulas de Educação } \\
\text { Física. Seibel e Fensterseifer } \\
\text { (2017) }\end{array}$ & Estudo de caso & Ensino Fundamental & $\begin{array}{l}\text { Boomerang do } \\
\text { Instagram, Câmera } \\
360^{\circ} \text {, leitor de QR } \\
\text { Code }\end{array}$ \\
\hline $\begin{array}{l}\text { 5.Base Nacional Comum } \\
\text { Curricular e os Exergames - } \\
\text { o que licenciados de } \\
\text { educação física falam sobre } \\
\text { a sua aplicabilidade. Souza } \\
\text { e Ramalho (2020) }\end{array}$ & $\begin{array}{l}\text { Método de teoria } \\
\text { estatística, tendo como tipo } \\
\text { de amostragem por } \\
\text { conveniência. Entrevistas } \\
\text { com } 10 \text { alunos do curso de } \\
\text { Licenciatura em Educação } \\
\text { Física }\end{array}$ & $\begin{array}{l}\text { Estudantes de } \\
\text { graduação EF }\end{array}$ & Exergames (EXGs) \\
\hline $\begin{array}{l}\text { 6.Uso das Tecnologias nas } \\
\text { Aulas de Educação Física } \\
\text { Escolar. Rohden (2017) }\end{array}$ & Investigação bibliográfica & Professores formados & Exergames \\
\hline $\begin{array}{l}\text { 7.As Tecnologias nas Aulas } \\
\text { de Educação Física Escolar. } \\
\text { Carvalho (2017) }\end{array}$ & Estudo qualitativo & $\begin{array}{l}\text { Professores EF } \\
\text { educação básica }\end{array}$ & Jogos digitais \\
\hline
\end{tabular}




\begin{tabular}{|c|c|c|c|}
\hline $\begin{array}{l}\text { 8.Innovation in Physical } \\
\text { Education: Teachers' } \\
\text { Perspectives on Readiness } \\
\text { for Wearable Technology } \\
\text { Integration Almusawi et al. } \\
\text { (2021) }\end{array}$ & $\begin{array}{l}\text { Estudo de caso } \\
\text { fundamentado em lógica } \\
\text { de indução analítica }\end{array}$ & $\begin{array}{l}\text { Professores de } \\
\text { educação física }\end{array}$ & Tecnologia vestível \\
\hline $\begin{array}{l}\text { 9.O Duplo Aspecto } \\
\text { Educativo Dos Jogos } \\
\text { Digitais Como Vivência De } \\
\text { Lazer De Crianças E } \\
\text { Jovens. Monteiro e Santos } \\
\text { (2021) }\end{array}$ & $\begin{array}{l}\text { A pesquisa exploratória e } \\
\text { descritiva }\end{array}$ & $\begin{array}{l}6^{\circ} \text { ano Ensino } \\
\text { Fundamental }\end{array}$ & Jogos digitais \\
\hline $\begin{array}{l}\text { 10.Tecnologias da } \\
\text { Informação e Comunicação } \\
\text { e Educação Física: } \\
\text { currículo, pesquisa e } \\
\text { proposta pedagógica. } \\
\text { Dambros e Oliveira (2016) }\end{array}$ & & $\begin{array}{l}\text { Analisou presença } \\
\text { das TIC nos } \\
\text { currículos de cursos } \\
\text { de licenciatura em } \\
\text { Educação Física }\end{array}$ & $\begin{array}{l}\text { Blogs } \\
\text { Materiais didáticos } \\
\text { digitais }\end{array}$ \\
\hline
\end{tabular}

Fonte: Elaborada pelas autoras

\section{PESQUISAS ENVOLVENDO O USO DE TECNOLOGIA DIGITAL NA EDUCAÇÃO FÍSICA}

A pesquisa sobre os trabalhos descritos neste contexto mostra uma área em ascensão, evidenciando a relação entre a tecnologia e a sua importância na Educação Física. O referencial encontrado aponta para o crescente uso da tecnologia digital na Educação Física.

Fuzaro, Santos e Monteiro (2021) realizaram análise bibliográfica para conhecer quais estudos na área da Educação Física (EF) interage com as tecnologias atuais. O Quadro 1 apresenta as lacunas para futuras pesquisas.

Quadro 1: Tendências e oportunidades relacionando os gaps científicos a partir de 6 (seis) artigos pesquisados por Fuzaro, Santos e Monteiro (2021).

\begin{tabular}{|l|}
\hline \multicolumn{1}{|c|}{ Foco no aluno FNA } \\
\hline Pesquisar se as TICs ajudam a desenvolver habilidades motoras. \\
\hline Pesquisar formas para alfabetização em nível diferenciado de TICs. \\
\hline Pesquisar o impacto das TICs nas habilidades cognitivas e no desempenho motor dos alunos. \\
\hline Investigar o que os alunos de EF acham das TICs na EF \\
\hline \multicolumn{1}{c|}{ Foco no professor FNP } \\
\hline Propor modelos para ministrar aulas com TICs. \\
\hline $\begin{array}{l}\text { Desenvolver reconhecimento das TICs no ensino e administração dos professores. } \\
\text { Desenvolver formas dos professores de EF distinguirem as diferentes TICs. Provar empiricamente o } \\
\text { posicionamento dos professores de EF sobre as TICs e suas aplicações. }\end{array}$ \\
\hline
\end{tabular}




\begin{tabular}{|l|}
\hline \multicolumn{1}{|c|}{ Foco na criação e padronização do(s) material (is) e método(s) “CPMM" } \\
\hline Desenvolver padronização de hardwares e softwares. \\
\hline Pesquisar formas comprobatórias da melhora do aprendizado por meio das TICs. \\
\hline Aprofundar a relação das TICs na EF. Comparar modelos de blogs e suas respectivas eficiências. \\
\hline Propor avaliação de TICs como pré-teste e pós-teste. \\
\hline Estudo testou um modelo integrativo sobre o impacto das TICs no desempenho em EF. \\
\hline Pesquisar as vantagens das TICs na EF. \\
\hline
\end{tabular}

Fonte: FUZARO, SANTOS E MONTEIRO (2021).

Segundo os autores, a relação entre as TIC e a EF, é insuficientemente pesquisada, necessitando de estudos sobre o uso das tecnologias no desenvolvimento das capacidades corporais nas aulas de EF. Destaca quanto à subjetividade pedagógica e especificidade da EF: “a qual está intimamente atrelada às práticas corporais, possui dificuldades ímpares na tentativa de perceber, entender e utilizar os recursos tecnológicos nas aulas" (FUZARO, SANTOS e MONTEIRO, 2021, p. 310). O autor enfatiza que acrescida às dificuldades citadas, em grande parte, existem restrições nas aulas referentes à infraestrutura física e material de acesso ao docente. Além disso, pontua que falta um profissional que dê o suporte técnico para o uso adequado dos recursos. A concepção dos professores em relação ao uso das novas tecnologias associa-se às restrições acima levantadas.

Um trabalho recente de Fukugauti e Pavan (2020) investigou quais requisitos são necessários à formação dos alunos, para corresponderem às demandas contemporâneas e da disciplina Educação Física, enquanto componente curricular obrigatório na Educação Básica. Os autores abordaram dois enfoques: a importância da tecnologia na formação dos alunos no século XXI; como os alunos lidam quando submetidos a trabalhos de Educação Física em plataformas digitais.

Encontraram resultados positivos em relação à renovação da prática pedagógica mudando a dinâmica da disciplina, consideraram o desenvolvimento das habilidades cognitivas dos alunos em todas as categorias da Dimensão do Conhecimento e da Dimensão do Processo Cognitivo (Taxonomia de Bloom) e à avaliação positiva da disciplina. Em suas análises sobre a diferença com o uso de tecnologias nas aulas da disciplina, um percentual de $(94,44 \%)$, afirmou ser benéfico o uso da tecnologia, pois de acordo com eles, as tarefas podem ser realizadas em casa pelos celulares e computadores aproveitando as aulas para atividades práticas tornando o aprendizado mais dinâmico e interativo.

Um estudo estatístico desenvolvido por Moreno et al. (2020) averiguou publicações na Web of Science (WoS) sobre tecnologia e em realidade aumentada ou virtual em EF. Os dados demostraram apesar de que os estudos sobre tecnologia em EF (461 artigos) tenham começado a 
se consolidar nos últimos cinco anos, apresentando um aumento significativo em 2015; sendo os EUA o país mais influente nesta área. Eles referem que as pesquisas específicas sobre o uso de realidade aumentada (AR) e realidade virtual (VR) estão em um estágio muito inicial, encontrando um total de22 artigos, que na visão dos autores caracteriza um baixo crescimento no ano de 2017. A partir dos resultados da análise bibliográfica, pontuaram que a Espanha continua se destacando por ser o país com mais pesquisas no assunto. Os autores salientam a premência de pesquisas, a fim de que se ambicione o fortalecimento nesta área.

O estudo desenvolvido por Seibel e Fensterseifer (2017), buscou entender a aplicabilidade das Tecnologias Digitais da Informação e Comunicação (TDIC) como instrumento de mediação da aprendizagem nas aulas de Educação Física. Utilizaram aplicativos gratuitos que foram instalados nos telefones dos próprios alunos como: Boomerang do Instagram ${ }^{3}$, Câmera $360^{\circ 4}$, leitor de QR Code ${ }^{5}$. A partir das vivências e trocas realizadas entre conversas e gravações das atividades e dos movimentos vivenciados, demonstraram ganhos na aprendizagem.

As atividades desenvolvidas por Seibel e Fensterseifer (2017) são relatas a seguir, pois apresentam contribuições para professores que desejem aplicar a tecnologia em suas aulas. Realizaram 6 (seis) aulas com alunos do $9^{\circ}$ ano do Ensino Fundamental. Previamente, aos encontros, solicitaram aos alunos que criassem um grupo no Whatsapp com professor de Educação Física, alunos e pesquisadores; este grupo foi usado para compartilhamento das imagens, vídeos, dúvidas que a cada aula eram postadas. Conforme relato dos pesquisadores, em todas as intervenções, como chamaram as aulas, explicaram antes as tarefas, bem como conversaram após as mesmas. Detectaram elevado grau de cooperação e entusiasmo denotados no feedback dos alunos. Os autores relataram que a aulas ficaram mais interessantes e que contribui para inovação na aprendizagem.

$\mathrm{Na}$ primeira aula a tarefa em grupo foi realizar 3 exercícios e filmar com Boomerang do Instagram. Na segunda aula, os pesquisadores compartilharam fotos de posições no Slackline, e novamente em grupo deveriam escolher posições de equilíbrio na fita, tirar foto e postar no grupo. Na terceira aula com apoio da Câmera Cardbord, foi solicitado que realizassem movimentos variados e filmassem em $360^{\circ}$. Na quarta aula com o suporte do aplicativo Pedômetro, os alunos percorriam 10 minutos de caminhada, após foi aferida as medidas de

\footnotetext{
${ }^{3}$ Aplicativo para criar vídeos pequenos e cativantes que fazem um loop para frente e para trás, e compartilhar. Disponível em:< https://play.google.com/store/apps/details?id=com.instagram.boomerang\&hl=pt_BR\&gl=US

4 As câmeras Cardbord $360^{\circ}$ funcionam de forma diferente dos dispositivos tradicionais. Esses dispositivos eletrônicos portáteis registram todas as direções e sentidos ao mesmo tempo, conseguindo capturar imagens de maneira semelhante ao ponto de vista do olho humano.

${ }^{5}$ O QR Code é um código de barras em 2D apresentado em forma digital ou impressa e que, ao ser lido, permite abrir links para páginas da Internet, imagens, textos e conteúdos diversos pelo celular.
} 
distância, gasto calórico. Na quinta aula, numa sala de vídeo realizaram dança e esporte com suporte do videogame Xbox 360 com Kinnect, um sensor de movimento. Na sexta aula, após baixarem o aplicativo de leitura Qr Code, os pesquisadores disponibilizaram diversos códigos no grupo de Whastapp de dança e movimentos corporais variados, nos quais os alunos imitariam após lerem com leitor. A Tabela 2 apresenta um resumo das aulas, com a tecnologia empregada, a atividade e a forma que usaram a tecnologia.

Tabela 2 - Número de aulas, tecnologia, atividade e métodos.

\begin{tabular}{|l|l|l|l|}
\hline Número de aulas & Tecnologia & Local & Método/Atividade \\
\hline Aula 1 & $\begin{array}{l}\text { Celular c/aplicativo: } \\
\text { Boomerang do } \\
\text { Instagram }\end{array}$ & Academia ao ar livre & $\begin{array}{l}\text { Filmagem dos } \\
\text { exercícios na } \\
\text { academia }\end{array}$ \\
\hline Aula 2 & Celular com câmera & $\begin{array}{l}\text { Área verde com uso } \\
\text { de slackline }\end{array}$ & $\begin{array}{l}\text { Foto do movimento } \\
\text { na fita de equilíbrio }\end{array}$ \\
\hline Aula 3 & $\begin{array}{l}\text { Aplicativo Câmera } \\
\text { Cadbord: fotos 360 }\end{array}$ & Na escola & $\begin{array}{l}\text { Registro exercícios } \\
\text { físicos variados }\end{array}$ \\
\hline Aula 4 & $\begin{array}{l}\text { Aplicativo Pedômetro } \\
\text { para medir distância, } \\
\text { velocidade e calorias. }\end{array}$ & No ginásio da escola & $\begin{array}{l}\text { Avaliar caminhada ou } \\
\text { corrida com } \\
\text { aplicativo }\end{array}$ \\
\hline Aula 5 & $\begin{array}{l}\text { Videogame Xbox 360 } \\
\text { com Kinnect c/sensor } \\
\text { movimento }\end{array}$ & $\begin{array}{l}\text { Na sala de vídeo da } \\
\text { escola }\end{array}$ & $\begin{array}{l}\text { Dança e esportes } \\
\text { variados com } \\
\text { videogame }\end{array}$ \\
\hline Aula 6 & $\begin{array}{l}\text { Leitor QR Code } \\
\text { Na escola }\end{array}$ & $\begin{array}{l}\text { Visualizar com Qr } \\
\text { Code e interpretar } \\
\text { com movimento } \\
\text { posturas de ginástica }\end{array}$ \\
\hline
\end{tabular}

Fonte: SEIBEL E FENSTERSEIFER (2017)

Souza e Ramalho (2020) pesquisaram as possibilidades de utilização dos Exergames (EXGs) pelos docentes de Educação Física em formação em suas respectivas aulas, partindo do referencial proposto na BNCC que contempla os Objetos de Conhecimento-Jogos Eletrônicos. Utilizaram o método de teoria estatística, tendo como tipo de amostragem por conveniência, seleção de elementos a que tem acesso, supondo que estes possam, de alguma forma, representar o universo (GIL 2008). A amostra da pesquisa foi composta por dez alunos do Curso de Licenciatura em Educação Física de uma Universidade Estadual, os quais aplicaram as entrevistas. De acordo com resultados encontrados, a totalidade dos alunos considerou que os Exergames contribuem para o ensino dos esportes, já uma porcentagem menor, cerca de $70 \%$ (setenta por cento) vislumbra o uso de Exergames nas suas aulas. Complementam seus achados, concluindo que a utilização dos Exergames pode ser um recurso tecnológico factível na Educação Física.

Rohden (2017) fez uma investigação bibliográfica acerca de recursos tecnológicos nas aulas de Educação Física e Exergames. Convidou pelo Facebook e pelo Watsapp os docentes da rede municipal de Ensino de Joinville, atuantes no Ensino Fundamental. No questionário pediu para mencionarem a respeito da usabilidade da tecnologia nas aulas de Educação Física com 
objetivos pedagógicos e usados pelos alunos. Em seus achados bibliográficos pontuou que com os consoles de Exergame, outras capacidades físicas são necessárias como a resistência, coordenação motora ampla, velocidade, força, equilíbrio e a flexibilidade, desta forma auxiliando na manutenção da atividade física e configuram-se como poderosas ferramentas para uso pedagógico e se encontram pouco explorados no cotidiano das escolas brasileiras.

Em outro trabalho de pesquisa bibliográfica desenvolvida por Carvalho $(2015,2017)$ são levantados os benefícios de mediar às aulas de Educação Física com ênfase nos jogos virtuais e digitais, como no caso do Dance Dance Revolution (DDR) que com a possiblidade de captar os movimentos e apresentar propostas como a dança contribui para o gasto energético e diminuição do comportamento sedentário.

A pesquisa pontua sobre a Educação Híbrida, que em 2015 e 2017 era mais estabelecida no Ensino Superior. No entanto, nos últimos 2 anos observou-se uma crescente desta metodologia de ensino na Educação Básica, cujo ensino foi desenvolvido presencialmente e online.

Segundo o autor, por meio de um ambiente virtual, pode haver ampliação das discussões, diálogo e potencialização das interações sociais. Contudo, refere que devem ser instituídas regras de participação neste ambiente. Destaca que mesmo diante das possiblidades, variabilidade e abrangência de jogos e metodologias acarretarem diferentes maneiras de proposição do conteúdo, a responsabilidade continua sendo do docente de sistematizar e unir os conteúdos às tecnologias junto ao aluno.

Em estudo desenvolvido num país do Oriente Médio as preocupações são semelhantes ao Brasil, no que concerne à prontidão dos professores de Educação Física quanto à aplicabilidade da tecnologia em suas aulas. Almusawi et al. (2021) pesquisaram a concepção dos docentes de Educação Física em relação a sua presteza para usar e integrar a tecnologia vestível como uma inovação na área.

As tecnologias vestíveis são dispositivos usados próximos ao corpo, fornecendo aos usuários dados e informações que podem melhorar a aprendizagem de várias maneiras. Com perspectivas educacionais em áreas de interação professor-aluno, envolvimento, avaliação e feedback, essas tecnologias oferecem soluções inovadoras e práticas para desenvolvimento de atividades educacionais e a respectiva avaliação na área de Educação Física (ALMUSAWI et al. 2021).

Consideraram que a capacidade do dispositivo de rastrear e promover exercício físico e atividade diária foi fundamental para oportunizar o uso de tecnologia vestível em Educação Física. Além disso, destacam que os sensores incorporados fornecem várias informações sobre indicadores de saúde, e podem ser utilizados pelos alunos no ambiente doméstico, evitando o comportamento sedentário (ALMUSAWI et al. 2021). 
De acordo com os pesquisadores, a fim de se almejar um ambiente de aprendizagem inovador, que integre a tecnologia vestível na educação física, são necessários quatro contextos principais: (a) ambiente de aprendizagem baseado em colaboração para encorajar experiências de aprendizagem conjunta e compartilhada entre alunos e seus colegas, professores e sistemas de apoio; (b) ambiente de aprendizagem baseado em competição e experiências de aprendizagem que contribuam para promover o entusiasmo do aluno; (c) ambiente de aprendizagem baseado em engajamento para chamar a atenção dos alunos e mantê-los engajados; e (d) ambiente de aprendizagem baseado em evidências para registrar o desempenho e fornecer evidências para moldar a motivação do aluno (ALMUSAWI et al. 2021).

Monteiro e Santos (2021) pesquisaram a dualidade percebida na acessibilidade dos jogos digitais na educação: a educação para o lazer e a educação pelo lazer. Investigaram como ocorre a inserção dos jogos digitais nas atividades de lazer de crianças e jovens. Como instrumento de pesquisa aplicou um questionário num total de 35 estudantes (meninos e meninas de 10 a 14 anos) do $6^{\circ}$ ano do Ensino Fundamental. A partir dos seus resultados identificaram a mediação familiar e domiciliar no princípio da educação para os jogos digitais, bem como a presença dos círculos de amizades e das tecnologias nesse processo.

De acordo com os autores, após análise das respostas dos estudantes, a iniciação aos jogos digitais ocorre na primeira infância; ou seja, as crianças recebem o dispositivo e a instrução dos pais para seu uso. À medida que vão crescendo, os amigos e as relações advindas do próprio ato de jogar somam-se as influências mediadoras. Outro aspecto destacado é que atualmente os pais ficam mais horas trabalhando e para compensar a ausência com os filhos, ofertam-lhes insumos tecnológicos. Nesse sentido, na visão da pesquisa, as crianças começam sua interação educativa não formal com tenra idade e ao entrarem na escola, na educação formal, só terão acesso aos jogos digitais no $6^{\circ}$ ano do Ensino Fundamental, ou seja tardiamente. Diante de tais reflexões os autores pontuaram “... a ausência da escola, da Educação Física e, principalmente, do Estado como instituições e ambiências mediadoras da formação cultural infanto-juvenil para, com e sobre o universo lúdico digital" (MONTEIRO e SANTOS, 2021 p. $545)$.

A vivência das autoras permite destacar que a relevância da mediação familiar no que tange à educação para o uso apropriado de jogos digitais é limitada pois na medida em que os filhos crescem desenvolvem uma autonomia em relação ao uso de recursos tecnológicos que, muitas vezes, superam o conhecimento dos pais e a influência dos círculos de amizades começa a ter preponderância sendo muitas vezes até obliterativo em relação à influência familiar.

Dambros e Oliveira (2016) abordaram os enfoques didáticos nas associações entre as Tecnologias da Informação e Comunicação e a área da Educação Física. Analisaram a presença das TIC nos currículos de cursos de graduação em Educação Física, bem como investigaram a incorporação do assunto, TIC e Educação Física, em outros coletivos de pesquisa no Brasil. Os 
resultados demonstram que algumas instituições brasileiras sofrem com esta carência; entretanto, destaca a necessidade de estimular projetos de inclusão, na licenciatura e em grupos de pesquisa nesta área.

\section{RESULTADOS E DISCUSSÕES}

Os resultados sugerem o crescimento de trabalhos envolvendo o uso da Tecnologia na Educação Física. A partir da análise dos dados elencados na tabela 1: Relação autor, tipo de estudo e tecnologia aplicada foram analisados diversos estudos.

O trabalho desenvolvido por Fuzaro, Santos e Pavan (2021) sugere lacunas a serem preenchidas em futuras pesquisas. Conforme descrito pelo autor e apresentados no Quadro 1, estas lacunas são classificadas em: foco no aluno, foco no professor, foco na criação e padronização de materiais e métodos. $\mathrm{O}$ foco no aluno priorizam pesquisas que analisem se as TICs ajudam a desenvolver habilidades motoras, pesquisam o impacto das TICs nas habilidades cognitivas e no desempenho motor dos alunos. Além disso, investiguem o que os alunos de EF acham das TICs na EF. O foco no professor sugere modelos para planejar e desenvolver aulas com TICs em EF, desenvolver reconhecimento das possibilidades de uso de TICs no ensino e administração dos professores de EF, bem como formas dos professores de EF conhecerem as possibilidades das diferentes TICs.

Contemplando tecnologias acessíveis e populares para os usuários, um dos artigos faz referência ao: Boomerang do Instagram, Câmera $360^{\circ}$, leitor de QR code. Outro demonstrou a Tecnologia Vestível (Wearable Technology) e suas contribuições para a saúde e o maior envolvimento nas atividades físicas. Também foram encontrados estudos mostrando o uso de tecnologias para a disponibilização de materiais didáticos e resultados de trabalhos realizados pelos próprios alunos, tais como vídeos sobre exercícios criados por eles. A nuvem de palavras abaixo apresenta as tecnologias utilizadas e o grau de frequência, que é representado pelas maiores fontes.

\section{Figura 3 - Nuvem de Palavras}

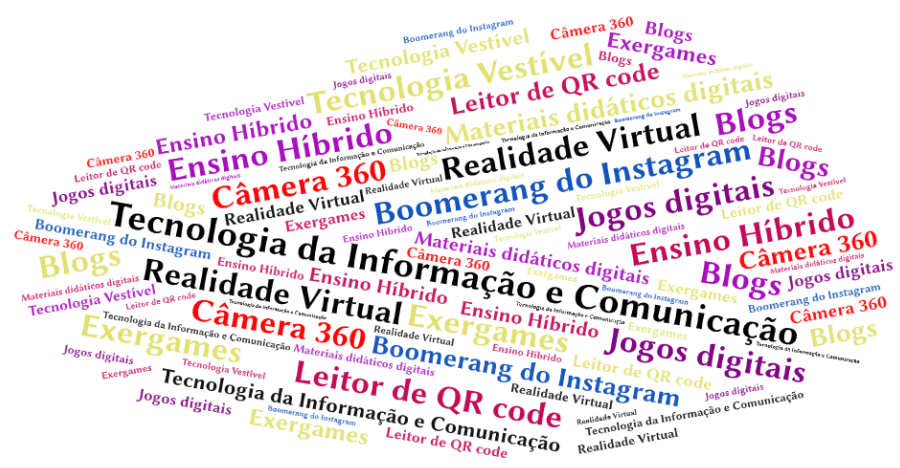


Fonte: Elaborada pelas autoras

A análise dos trabalhos pesquisados apontou questão de entraves em relação ao uso de TIC na EF. Foi constatado que além das contribuições nos processos de ensino e aprendizagem existem dificuldades em relação ao uso de TIC na EF.

Carvalho (2017) destaca um empecilho para a TIC na Educação Física, ao mencionar que para alguns, o pensamento de que o cerne da Educação Física é colocar o corpo em movimento. Em consequência, as iniciativas de interação com jogos virtuais nas aulas, são vistas como uma distorção do real objetivo da disciplina na escola. O autor coloca a limitação na utilização das TIC apenas para planejamento e organização das aulas, não evoluindo para outros usos.

Corroborando com Fuzaro et al. (2021); o estudo de Almusawi et al. (2021), sugere que a concepção de professores e equipes diretivas é de que a Educação Física é uma disciplina prática com uso mínimo ou inexistente de tecnologia. $\mathrm{O}$ autor ressalta que, embora os professores de Educação Física interajam com a tecnologia diariamente (como usando seus telefones celulares, e mais especificamente periféricos vestíveis, como fones de ouvido sem fio e Smartwatches), há um consenso geral no estudo de que a integração da tecnologia na Educação Física depende do desenvolvimento profissional por meio de treinamentos, seminários, workshops ou qualquer meio de preparação dos professores de Educação Física para integração de tecnologia.

Dambros e Oliveira (2017) perceberam uma discreta inserção das TIC nos currículos, grupos de pesquisa e propostas pedagógicas de Educação Física, embora como observado nos trabalhos correlatos, haja um potencial significativo e uma necessidade de ampliação do uso dos recursos tecnológicos por esta área de conhecimento.

Os estudos reforçam a urgência de formações para que os professores da área considerem-se aptos tecnologicamente e pedagogicamente para enfrentar alguns desafios que se apresentam (DAMBROS e OLIVEIRA 2017; FUZARO et al. 2021; ALMUSAWI et al. 2021).

No tocante às competências digitais dos professores, são necessários processos formativos, que desenvolvam e incentivem o uso dos recursos de Tecnologias de Informação e Comunicação (TIC), acessíveis como celulares, pois segundo Tarouco (2019, p. 44): “uma vez que é possível que não haja uma melhoria significativa na quantidade de recursos de TIC nas 
escolas em curto prazo. Por outro lado, o uso de celular para acesso à Internet pelos alunos e pelos próprios professores está amplamente disseminado".

Dentre os benefícios destacados na aprendizagem, observa-se que todos os trabalhos reportam a melhoria da aprendizagem, aumento na motivação dos alunos, melhora na percepção do cuidado da saúde, à medida que a tecnologia promove a possibilidade de acompanhamento/monitoração do movimento corporal.

Os benefícios levantados sobre os jogos digitais na EF são: desenvolver diferentes conteúdos, mudança na proposição e metodologia das aulas, aumento do movimento corporal, combate ao sedentarismo (CARVALHO, 2017; ROHDEN, 2017; SOUZA e RAMALHO 2020).

O uso de tecnologia vestível em Educação Física permite rastrear e promover exercício físico e atividade diária. Tornaram-se um tipo proeminente de tecnologia vestível para exercícios, pois motivam intrinsecamente a realização da atividade (ALMUSAWI, 2021).

Destacam-se as contribuições do trabalho de Seibel e Fensterseifer (2017) que utilizaram tecnologias de fácil instalação nos Smartphones, como o leitor de QR code, a Câmara $360^{\circ}$ e o Boomerang do Instagram que vem instalado no aplicativo, iniciativas simples no uso da tecnologia, que dinamizaram as aulas de Educação Física.

\section{CONSIDERAÇÕES E TRABALHOS FUTUROS}

As barreiras apontadas para inserção da tecnologia nos trabalhos pesquisados, entre os motivos de infraestrutura, têm suas raízes em uma das abordagens da Educação Física, vigente nos anos 80 e 90, a desenvolvimentista, que postula que o movimento corporal é o principal objetivo da Educação Física, sustentando a especificidade do seu objeto. Neste sentido, não se pode julgar a indisponibilidade ou vontade dos professores em diversificar suas aulas, mas entender este processo que tem suas formações arraigadas em tendências que numa época foram priorizadas pelo poder público.

As tecnologias abordadas nos trabalhos correlatos podem ser consideradas como tecnologias avançadas, que alguns trabalhos denominam de alta tecnologia "high tech", como no caso do Wearable Technology, os Exergames com seus últimos avanços na captação do movimento, bem como a realidade virtual. Estas tecnologias apresentam um grande potencial de inovação, mas requerem amplo conhecimento tecnológico; portanto um maior tempo de preparo e formação para os docentes.

Diante do potencial das tecnologias digitais, infere-se a importância dos estudos de revisão e a necessidade de pesquisas aplicadas envolvendo a tecnologia e Educação Física que considerem a realidade das escolas públicas e que contribuam para apropriação do 
conhecimento do docente, assim como dos alunos sobre a tecnologia digital, de maneira a almejar a inclusão digital dos mesmos.

Como parte da pesquisa ora relatada, existe a previsão da implantação de um ambiente de apoio à capacitação de docentes para o uso de Tecnologia na Educação Física. Este ambiente está em fase de implantação.

\section{REFERÊNCIAS}

ALMUSAWI, Hashem. DURUGBO, C.M. BUQAWA, Afaf. (2021). Innovation in Physical Education: Teachers' Perspectives on Readiness for Wearable Technology Integration. Computers \& Education. . 167. 10.1016/j.compedu. 2021.104185. Disponível em: < https://www.researchgate.net/publication/349754706_Innovation_in_Physical_Educatio n_Teachers'_Perspectives_on_Readiness_for_Wearable_Technology_Integration>. Acesso em: 18 de ago. 2021.

BRASIL. Base Nacional Comum Curricular: Educação é a base. Brasília: MEC, 2018. Disponível em:< http://basenacionalcomum.mec.gov.br/images/BNCC_EI_EF_110518_versaofinal_site. $\mathrm{pdf}>$

BRASIL. Secretaria de Educação Fundamental. Parâmetros curriculares nacionais: Educação Física / Secretaria de Educação Fundamental. Brasília: MEC / SEF, 1998. 114 p. Disponível em: $<$ http://basenacionalcomum.mec.gov.br/images/pcn/fisica.pdf $>$. Acesso em: 21 ago. 2021.

BRASIL. Base Nacional Comum Curricular: Educação é a base. Brasília: MEC, 2018. Tecnologias Digitais da Informação e Comunicação no contexto escolar: possibilidades. Disponível em: $<$ http://basenacionalcomum.mec.gov.br/pesquisar?q=Tecnologias\%20digitais $>$. Acesso em: 3 set. 2021.

CARVALHO, Arlindo Fernando Paiva. As Tecnologias nas Aulas de Educação Física Escolar. Revista Educação Pública. 2017. ISSN: 1984-6290. Disponível em:<https://educacaopublica.cecierj.edu.br/artigos/17/1/as-tecnologias-nas-aulas-deeducao-fsica-escolar>. Acesso: 08 ago. 2021.

CARVALHO, Arlindo Fernando Paiva. As Tecnologias nas Aulas de Educação Física Escolar. Anais do Congresso Brasileiro de Ciências do Esporte. XIX CONBRACE-IV CONICE. Vitória-RS, 2015. Disponível em:< http://congressos.cbce.org.br/index.php/conbrace2015/6conice/paper/viewFile/7740/383 >. Acesso em: 08 ago. 2021.

CORRÊA, Evandro Antonio. As tecnologias no processo de ensino escolar e a aprendizagem dos conhecimentos da Educação Física. Orientador: Dagmar Aparecida Cynthia França Hunger Tese (Doutorado Ciências da Motricidade)Universidade Estadual Paulista. Faculdade de Ciências, Bauru, 2018. 209 f. Disponível em:<

https://repositorio.unesp.br/bitstream/handle/11449/153276/corr\%C3\%AAa_ea_dr_baur u.pdf? sequence=3\&isAllowed=y $>$ Acesso em 07 out. 2021 . 
DAMBROS, Daniela D. OLIVEIRA, Andréa M. Tecnologias da Informação e Comunicação e Educação Física: currículo, pesquisa e proposta pedagógica. Educação, Formação \& Tecnologias (janeiro-junho, 2016), 9 (1), 16-28. Disponível em: $<$ https://scholar.google.com.br/scholar_url?url=https://dialnet.unirioja.es/descarga/articu lo/5905496.pdf\&hl=ptR\&sa=X\&ei=Uw82YfOeHOuNy9YP8aigsAg\&scisig=AAGBfm 0FmHCi7Vnf82dBtByPtTsf67nMpQ\&oi=scholarr. Acesso: 08 ago. 2021.

DICIONÁRIO OXFORD. Tecnologia. Disponível em:<https://www.google.com/search?q=tecnologia+significado\&oq>. Acesso em: Set. 2021.

FUZARO, T. C., SANTOS, E. F. dos. MONTEIRO, M. A. A. (2021). Tecnologia da informação e comunicação: novas tendências do ensino na educação física. REVISTA INTERSABERES, 16 (37), 306-327. Disponível em: https://doi.org/10.22169/revint.v16i37.1969. Acesso em: 15 jul. 2020.

FUKUGAUTI, Rodrigo. PAVAN, Fernanda S. Tecnologia na Educação Física Escolar. In: Educação física e áreas de estudo do movimento humano 4 [recurso eletrônico] / Organizador MATTOS, Samuel Miranda. - Ponta Grossa, PR: Atena, 2020. Página 59-85. Disponível em: <

https://sistema.atenaeditora.com.br/index.php/admin/api/artigoPDF/35235> Acesso em: 14 jul. 2020.

GIL, Antônio Carlos. Métodos e técnicas de pesquisa social. São Paulo: Atlas, 2008.

KITCHENHAM, B., BRERETON, O. P., BUDGEN, D., TURNER, .,BAILEY , J., and Linkman, S. (2009). Systematic literature reviews in software engineering - a systematic literature review. Information and software technology, 51(1):7-15.

MORENO, F. C. SERRANO, M. H. G. FOMBONA, J. TASCÓN, M. G., 2020. "The Emergence of Technology in Physical Education: A General Bibliometric Analysis with a Focus on Virtual and Augmented Reality," Sustainability, MDPI, Open Access Journal, vol. 12(7), pages 1-23, March. Disponível em:< https://ideas.repec.org/a/gam/jsusta/v12y2020i7p2728-d339032.html> . Acesso em: 16 ago. 2021.

MONTEIRO, V. A. do N.; SANTOS, S. M. dos. O Duplo Aspecto Educativo dos Jogos Digitais como Vivência de Lazer de Crianças e Jovens. LICERE - Revista do Programa de Pós-graduação Interdisciplinar em Estudos do Lazer, [S. l.], v. 24, n. 2, p. 545-578, 2021. DOI: 10.35699/2447-6218.2021.34961. Disponível em: <https://periodicos.ufmg.br/index.php/licere/article/view/34961>. Acesso em: 17 set. 2021.

ROHDEN, Rafael. Uso das Tecnologias nas Aulas de Educação Física Escolar. TCC UFSC 2017. Orientadora: Dra. Tatiana Renata Garcia. Disponível em: <https://repositorio.ufsc.br/bitstream/handle/123456789/182262/Artigo-RafaelRohden.pdf?sequence=1\&isAllowed=y >. Acesso em: 15 jul. 2021.

SEIBEL, D. A.; FENSTERSEIFER Isse, S. Tecnologias Digitais: Ferramenta Pedagógica para as Aulas de Educação Física. Revista Didática Sistêmica, [S. l.], v. 19, n. 1, p. 68-82, 2017. DOI: 10.14295/rds.v19i1.7222. Disponível em: <https://periodicos.furg.br/redsis/article/view/7222>. Acesso em: 27 jul. 2021. 
SOARES, K. M., \& PROCASKO, J. C. S. R. (2019). A Inserção da Tecnologia no Ensino Fundamental: Reflexões a partir da práxis pedagógica. Poíesis Pedagógica, 16(2), 15-28. Disponível em:< https://doi.org/10.5216/rpp.v16i2.55655> . Acesso em: Set. 2021.

SOTILI, Lucilaine. STÖER, Jessica Ferreira. PINHEIRO, Izoldi Klein.

BENVENUTTI, Dilva Bertoldi. Ensino híbrido na rede pública em tempos de pandemia: reflexões e possibilidades. Cadernos do Aplicação https://seer.ufrgs.br/CadernosdoAplicacao Publicação Ahead of Print ISSN 2595-4377 (online) Porto Alegre | jul-dez. 2021 | v.34 | n.2.; Disponível em: < https://seer.ufrgs.br/CadernosdoAplicacao/article/view/114126/64892>. Acesso em: 05 jan. 2022.

SOUZA, O. T. de; RAMALHO, C. Base Nacional Comum Curricular e os Exergames O Que Licenciandos de Educação Física Falam Sobre A Sua Aplicabilidade. Revista Eletrônica Nacional de Educação Física, [S. l.], v. 9, n. 14, p. 54-67, 2020. DOI: 10.46551/rn2019091400035. Disponível em:

https://www.periodicos.unimontes.br/index.php/renef/article/view/2784. Acesso em: 28 jul. 2021.

TAROUCO, Liane Margarida Rockenbach. Um panorama da fluência digital na sociedade da informação. In: BEHAR, P. Alejandra. (Org.) Competências Educação à distância. Porto Alegre. Penso, 2013.

TAROUCO, Liane Margarida Rockenbach. Competências digitais dos professores. In: Alexandre F. Barbosa. (Org.). Pesquisa sobre o uso das tecnologias de informação e comunicação nas escolas brasileiras: TIC educação 201. 1ed.São Paulo: Comitê Gestor da Internet no Brasil, 2019, v. 2019, p. 33-44. Disponível em:< https://cetic.br/media/docs/publicacoes/216410120191105/tic_edu_2018_livro_eletroni co.pdf> . Acesso: 11 nov. 2021. 